\title{
Factors that influence biological survival in rheumatoid arthritis: results of a real-world academic cohort from the Netherlands
}

\author{
Elise van Mulligen ${ }^{1}$ (D) $\cdot$ Saad Ahmed ${ }^{1} \cdot$ Angelique E. A. M. Weel $^{1,2,3} \cdot$ Johanna M. W. Hazes $^{1}$. \\ Annette H. M. van der Helm- van Mil ${ }^{1,4}$ • Pascal H. P. de Jong ${ }^{1}$
}

Received: 19 October 2020 / Revised: 18 December 2020 / Accepted: 22 December 2020 / Published online: 7 January 2021

(C) The Author(s) 2021

\begin{abstract}
We aim to explore real-world biological survival stratified for discontinuation reason and determine its influenceability in rheumatoid arthritis (RA) patients. Data from the local pharmacy database and patient records of a university hospital in the Netherlands were used. RA patients who started a biological between 2000 and 2020 were included. Data on age, anti-citrullinated protein antibody (ACPA) and rheumatoid factor (RF) status, presence of erosions, gender, body mass index, time to first biological, biological survival time, use of csDMARDs, and discontinuation reasons were collected. Of the included 318 patients, $12 \%$ started their first biological within 6 months after diagnosis. The median time to first biological was 3.6 years (95\% CI, 1.0-7.2). The median survival of the first- and second-line biological was respectively 1.7 years (95\% CI, 1.3-2.2) and 0.8 years (95\% CI, 0.5-1.0) $(p=0.0001)$. Discontinuation reasons for the first-line biological were ineffectiveness $(47 \%)$, adverse events $(17 \%)$, remission (16\%), pregnancy (30\%), or patient preference (10\%). Multivariable Cox regression analyses for discontinuation due to inefficacy or adverse events showed that concomitant use of csDMARDs $(\mathrm{HR}=1.32, p<0.001)$ positively while RF positivity negatively $(\mathrm{HR}=$ $0.82, p=0.03$ ) influenced biological survival. ACPA positivity was associated with the inability to discontinue biologicals after achieving remission $(\mathrm{HR}=1.43, p=0.023)$. Second-line TNF inhibitor survival was similar between patients with a primary and secondary non-response on the first-line TNF inhibitor $(\mathrm{HR}=1.28, p=0.34)$. Biological survival diminishes with the number of biologicals used. Biological survival is prolonged if patients use csDMARDs. RF was negatively associated with biological survival. ACPA was negatively associated with the inability to discontinue biologicals after achieving remission. Therefore, tailoring treatment based upon autoantibody status might be the first step towards personalized medicine in RA.

\section{Key Points}

- Prolonged biological survival is a surrogate for treatment effectiveness; however, an increasing amount of patients will taper treatment due to remission, and factors influencing biological survival based on separate reasons for discontinuation have not been explored.

- We found that combining a biological DMARD with a conventional synthetic DMARD increases biological DMARD survival. Rheumatoid factor is negatively associated with biological survival. Anti-citrullinated protein antibody is negatively associated with the inability to discontinue the biological when remission was reached.

- The first step towards personalized medicine might be tailoring of treatment based upon autoantibody status.
\end{abstract}

Keywords bDMARDs $\cdot$ Biological survival $\cdot$ Rheumatoid arthritis $\cdot$ TNF inhibitor

Elise van Mulligen

elise.vanmulligen@erasmusmc.nl

1 Department of Rheumatology, Erasmus MC, Room Na-523, Postbus 2040, 3000 CA Rotterdam, the Netherlands

2 Department of Rheumatology, Maasstad Hospital, Rotterdam, the Netherlands

3 Erasmus School of Health Policy \& Management, Rotterdam, the Netherlands

4 Department of Rheumatology, LUMC, Leiden, the Netherlands

\section{Introduction}

Management of RA has improved in the last decades due to early diagnosis, a treat-to-target approach, and the introduction of biological disease-modifying anti-rheumatic drugs (bDMARDs) [1]. Tumor necrosis factor inhibitors (TNF inhibitors) were the first bDMARDs to be developed for rheumatic diseases and are currently most frequently prescribed after an inadequate response to conventional synthetic (cs)DMARDs. It has been suggested that prolonged biological 
survival is a surrogate for treatment effectiveness [2]. Since more patients reach remission nowadays, more patients will be able to taper and discontinue treatment [1]. Therefore, solely taking into account overall biological survival will dilute outcomes, and to properly analyze biological survival, results should be stratified according to discontinuation reasons.

Previous studies, based on biological registries throughout Europe, have shown that $50 \%$ of patients discontinue their TNF inhibitor within 3-5 years [3]. Main reasons for discontinuation were inefficacy and adverse events [3, 4]. Within trials and biological registries, longer survival times were seen for first-line biologicals and when bDMARDS were combined with csDMARDs [5-7]. However, factors influencing biological survival based on separate reasons for discontinuation have not been previously explored.

Therefore, the aim of this Dutch real-world rheumatoid arthritis cohort is to explore first- and second-line biological survival and to determine its influenceability when stratified for discontinuation reasons.

\section{Patients and methods}

\section{Study design}

Data from a retrospective cohort were used, which we derived from the local pharmacy database and patient records of the Erasmus MC, an academic hospital in the Netherlands. We included data from rheumatoid arthritis (RA) patients starting a biological between 2000 and 2020. We excluded patients for whom non-adherence was reported, and if start and stop dates for bDMARDs were not available. Standard treatment of RA in the Netherlands is based upon a treat-to-target approach aiming for low disease activity. Methotrexate, unless contraindicated, is the first choice of treatment after being diagnosed with RA. If the treatment target is not reached, another conventional synthetic (cs)DMARD can be started. If patients have an inadequate response to $>1$ csDMARD, a bDMARD can be prescribed. In case of an inadequate response, rheumatologists can prescribe another bDMARD with the same mode of action (cycling) or a bDMARD with another mode of action (switching) [8].

\section{Data collection}

Biological survival was the main outcome. Discontinuation was defined as skipping $\geq 2$ doses and/or $\geq 2$ months without biological treatment. Reasons for discontinuations were evaluated and classified into inefficacy, which we divided into primary ( $<6$ months) and secondary ( $\geq 6$ months) nonresponse; adverse events (AEs); remission; pregnancy; patient preference; and other reasons.

\section{Analyses}

We compared first- and second-line biological survival with Kaplan-Meier curves and with Wilcoxon-Breslow-Gehan tests at 3 years. Thereafter, first-line biological survival with and without concomitant use of csDMARD(s) was compared. Subsequently, we investigated whether primary and secondary inefficacy to a first-line TNF inhibitor leads to differences in second-line TNF inhibitor survival. Patients stopping their bDMARD due to remission or pregnancy were censored.

Cox proportional hazard models were used to estimate hazard ratios (HRs) of candidate baseline predictors (age, gender, ACPA, RF, erosions, BMI, DAS28, disease duration, or comedication) for bDMARD survival stratified for reasons for discontinuation, namely (1) inefficacy or adverse events and (2) remission. First univariable Cox regression analyses were performed, and candidate predictors with a $p<0.20$ were entered into a multivariable model, after which backward selection was applied until significance was reached. To prevent overfitting, an entry model was created and backward selection was applied. Schoenfeld residuals were assessed to check the proportional hazard assumption.

All data was analyzed using STATA 15. $p$ values $\leq 0.05$ were considered statistically significant.

\section{Results}

\section{Patients}

Data were derived from 318 RA patients (Table 1). Time until first bDMARD prescription remained constant between 2000 and 2020. In our cohort, $50 \%$ of patients started their first biological after 2013; thus, in most recent years, more bDMARDs were prescribed. A total of 39 (12\%) patients started their first bDMARD within 6 months after diagnosis.

\section{First- and second-line biological survival}

The median $(95 \% \mathrm{CI})$ survival time of the first-line biological was 1.7 years (1.3-2.2), and for the second-line bDMARD, 0.8 years $(0.5-1)$. The most prescribed first-line bDMARDs were etanercept (45\%), adalimumab (28\%), and certolizumab pegol (19\%) (Table 1). Since only 9\% of patients were using nonTNF inhibitors as second-line bDMARD, a direct comparison between a cycling and switching strategy could not be performed.

bDMARD survival was significantly longer for the firstline bDMARD compared to the second $(p=0.0001)$ (Fig. 1a). Discontinuation reasons for the first-line bDMARD were inefficacy (47\%), adverse events (17\%), remission (16\%), pregnancy $(30 \%)$, or patient preference $(10 \%)$. Discontinuation reasons for the second-line bDMARD were similar (supplemental table S1). 
Table 1 Characteristics of rheumatoid arthritis population using a biological in a university hospital

RA patients, $n=318$

\section{Demographic}

- Age at diagnosis, mean (SD)

$40.9(16)$

- Gender, female, $n(\%)$

$264(83)$

- BMI, mean (SD)

$26.9(6.3)$

Disease characteristics

- ACPA positive, $n(\%)$

$224(70)$

- RF positive, $n(\%)$

$226(71)$

- Erosive disease, $n(\%)$

$141(44)$

Medication

- Time to first biological (years), median (IQR)

$3.6(1-7)$

- First-line biologicals

○ Etanercept, $n(\%)$

$142(45)$

- Adalimumab, $n(\%)$

90 (28)

- Certolizumab pegol, $n(\%)$

59 (19)

- Infliximab, $n(\%)$

15 (5)

5 (2)

3 (1)

○ Anakinra, $n(\%)$

$66(21)$

147 (46)

53 (17)

o Other csDMARDs (SASP, HCQ, LEF), $n(\%)$

$52(16)$

$A C P A$ anti-citrullinated protein antibody, $B M I$ body mass index, CSDMARD conventional synthetic disease-modifying anti-rheumatic drug, $H C Q$ hydroxychloroquine, $I Q R$ interquartile range, $L E F$ leflunomide, $M T X$ methotrexate, $R F$ rheumatoid factor, $S A S P$ sulfasalazine, $S D$ standard deviation

\section{First-line biological survival with or without concomitant use of csDMARDs}

A total of $48(25.3 \%)$ and $6(15.4 \%)$ patients respectively with and without concomitant use of $\operatorname{csDMARD}(\mathrm{s})$ were still using their first-line biological after 3 years of follow-up. The median $(95 \% \mathrm{CI})$ survival time of the first-line bDMARD with csDMARD(s) was $2.0(1.3-2.3)$ years, and without csDMARDs, $1.0(0.5-5.3)$ year (Fig. $1 \mathrm{~b}, p=0.031)$. Firstline bDMARD survival was longest for treatment regimens with methotrexate (MTX) followed by other csDMARDs, and no csDMARD use (Fig. 1c). However, no significant differences were found between MTX and the other csDMARDs as concomitant therapy ( $p=0.14$ ) (Fig. 1c).

\section{Primary and secondary failure}

The median $(95 \% \mathrm{CI})$ survival time for the second-line TNF inhibitor was $0.42(0.25-1.58)$ years for patients with a primary non-response for the first TNF inhibitor and 0.92 $(0.83-1.83)$ years for patients with a secondary non-response for the first TNF inhibitor. Although overall survival time on the second-line biological did not differ significantly between patients with a primary and secondary non-response (HR 1.28, $p=0.34$ ), a trend could be observed (Fig. 1d).

\section{Predictors for biological survival}

Univariate Cox regression for discontinuation due to inefficacy and adverse events showed that $\mathrm{RF}(\mathrm{HR}=0.80, p=0.014)$ and presence of erosions (HR $=0.65, p<0.001$ ) were negatively associated with bDMARD survival. Concomitant use of $\operatorname{csDMARD}(\mathrm{s})(\mathrm{HR}=1.35, p<0.001)$ on the other hand was positively associated with bDMARD survival. The aforementioned factors as well as time to bDMARD, age, gender, and ACPA were included in our multivariable model with backward selection. In the final model, only $\mathrm{RF}$ ( $\mathrm{HR}=0.82, p=$ 0.03 ) and concomitant use of csDMARDs (HR $=1.32, p=$ 0.001 ) were significantly associated with bDMARD survival (Table 2). When we used an entry model and applied backward selection, the aforementioned predictors were again in the final model, but also the presence of erosions was included.

The same procedure was followed for investigating which factors were associated with a higher chance of discontinuing bDMARDs due to remission. Only a positive ACPA status was associated with longer biological survival due to inability to taper medication $(\mathrm{HR}=1.43, p=0.023)$ (Table 2).

\section{Discussion}

Optimal management of RA is based on reaching the lowest possible disease activity with a treat-to-target approach [1]. Despite the improved management approach and increasing treatment options, only $60-70 \%$ of RA patients will reach a long-term clinical response [4]. Within our study, we found a significant difference in survival time between the first- and second-line bDMARD, implicating the importance to prolong first-line bDMARD survival. Several factors can influence bDMARD survival of which some can be influenced.

Main reasons for discontinuation in our and in other studies were inefficacy and adverse events [3]. Primary inefficacy indicates no effect at all, and is thought to be due to a mismatch between the bDMARD and the specific RA subtype, causing the biologic agent not to be effective [9]. Secondary inefficacy indicates that the clinical response is first obtained, but not maintained, and is thought to be caused by formation of autoantibodies against the biologic [4]. Although we did not find a significant difference in second-line TNF inhibitor survival between RA patients with a primary or secondary non-response to the first TNF inhibitor, a trend could be observed. This was probably due to a low number of patients in 
a

First- and second-line biological survival

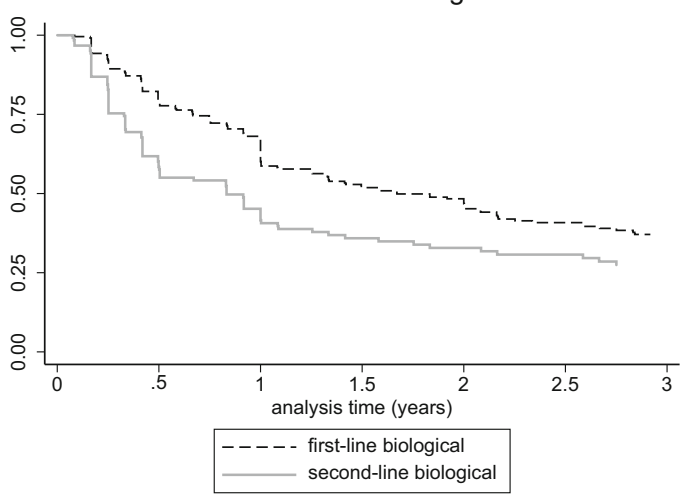

C

First-line biological survival stratified for combination therapy

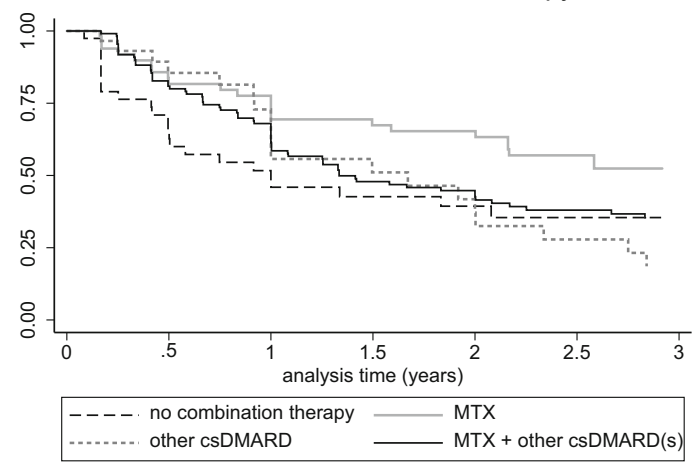

Fig. 1 Kaplan-Meier curves for biological survival. a Kaplan-Meier for first- versus second-line biological survival. b Kaplan-Meier curve of patients with or without combination therapy. $\mathbf{c}$ Kaplan-Meier curve of patients without combination therapy, and for patients with combination therapy stratified for methotrexate, methotrexate combined with one or

the group with a primary non-response for the first-line bDMARD $(n=42)$. However, these data indicate that rheumatologists should consider switching to another mode of action in case of primary inefficacy instead of cycling to another TNF inhibitor, but validation is needed [10,11].

Compared to previous findings, bDMARD survival seems to be short. This can be explained by the setting of our cohort in a tertiary care university hospital, which usually includes more difficult to treat and/or refractory RA patients. Furthermore, within an academic environment, patients are often participating in (treatment) trials, which could influence the results. For instance, the treatment in the Rotterdam Early Arthritis Cohort (tREACH) trial and the tapering strategies in RA (TARA) trial were initiated in the Erasmus MC $[12,13]$. Furthermore, the Erasmus MC participated in the POET trial, which was also a tapering trial [14]. However, these trials were all following a treat-to-target strategy, which probably did not influence our results much. Besides these trials, a large proportion of the patients discontinued their bDMARD due to pregnancy. This is related to the fact that Erasmus MC has an b

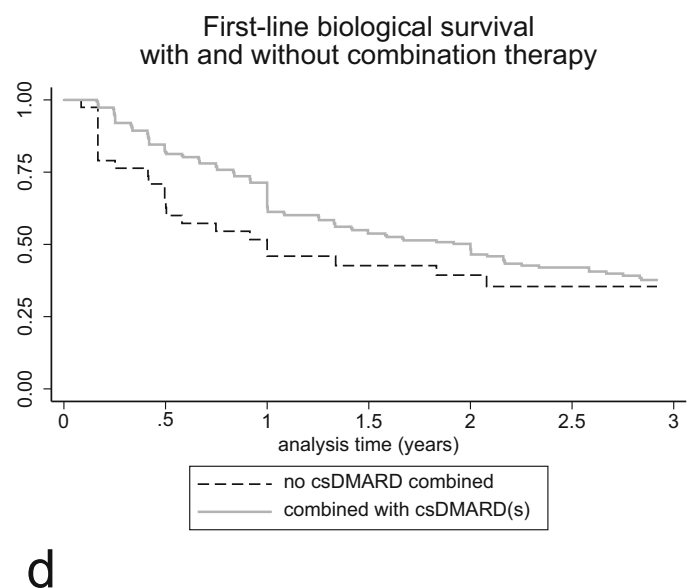

Second-line biological survival stratified for primary and secondary inefficacy for first-line biological

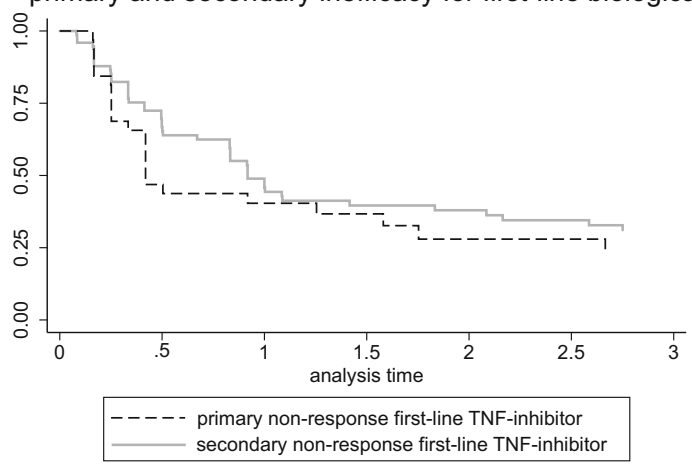

more other csDMARDs (sulfasalazine, hydroxychloroquine, and/or leflunomide), or one or more other csDMARDs. d Kaplan-Meier of second-line TNF inhibitor survival, stratified for primary and secondary inefficacy for the first-line TNF inhibitor. csDMARD, conventional synthetic disease-modifying anti-rheumatic drug; MTX, methotrexate

ongoing cohort for patients with a wish to conceive [15]. Consequently, a high number of patients were using certolizumab pegol, which is known to be safe to use during pregnancy.

Outcomes of our study on the other hand are in accordance with previous findings. Benefits of combining a bDMARD with a csDMARD have been previously described $[6,16$, 17]. Reasons for this synergistic effect are not fully understood. Soliman et al. investigated the csDMARDs separately and found the strongest effect on prolongation of biological survival when MTX was combined [16]. Unfortunately, we lacked power to confirm this for subgroups within the csDMARDs in our study. One of the reasons could be that csDMARDs can prevent development of neutralizing antidrug antibodies. It is also thought that csDMARDs affect clearance of the bDMARD by modulating either the expression of $\mathrm{Fc}$ receptors on monocytes or the interaction of the $\mathrm{Fc}$ receptor and the bDMARD [4].

Another factor that could influence biological survival is the degree of adherence. The longer a patient has the disease, 
Table 2 Predictors for overall biological survival

\begin{tabular}{|c|c|c|c|c|}
\hline & \multicolumn{2}{|l|}{ Univariable } & \multicolumn{2}{|l|}{ Multivariable $^{1}$} \\
\hline & $\operatorname{HR}(95 \% \mathrm{CI})$ & $p$ & $\mathrm{HR}(95 \% \mathrm{CI})$ & $p$ \\
\hline \multicolumn{5}{|c|}{ Biological survival taking into account discontinuation due to inefficacy or $\mathrm{AEs}^{2}$} \\
\hline Age at diagnosis & $1.00(1.00-1.01)$ & 0.514 & & \\
\hline Gender (female) & $1.00(0.82-1.23)$ & 0.985 & & \\
\hline BMI & $0.99(0.98-1.01)$ & 0.296 & & \\
\hline Rheumatoid factor & $0.80(0.67-0.96)$ & 0.014 & $0.82(0.69-0.98)$ & 0.03 \\
\hline ACPA & $0.90(0.75-1.07)$ & 0.223 & & \\
\hline Erosions & $0.65(0.55-0.76)$ & $<0.001$ & & \\
\hline Time to first-line biological & $0.98(0.95-1.01)$ & 0.163 & & \\
\hline Combination therapy & $1.35(1.14-1.59)$ & $<0.001$ & $1.32(1.13-1.57)$ & 0.001 \\
\hline DAS28 at time of discontinuation & $1.02(0.87-1.21)$ & 0.754 & & \\
\hline \multicolumn{5}{|c|}{ Prolonged biological survival due to inability to $\operatorname{taper}^{3}$} \\
\hline Age at diagnosis & $1.00(0.99-1.01)$ & 0.717 & & \\
\hline Gender (female) & $1.08(0.75-1.56)$ & 0.676 & & \\
\hline BMI & $0.98(0.95-1.01)$ & 0.175 & & \\
\hline Rheumatoid factor & $1.26(0.94-1.96)$ & 0.121 & & \\
\hline ACPA & $1.43(1.05-1.93)$ & 0.023 & $1.43(1.05-1.93)$ & 0.023 \\
\hline Erosions & $0.70(0.53-0.92)$ & 0.481 & & \\
\hline Time to first-line biological & $1.04(0.99-1.09)$ & 0.119 & & \\
\hline Combination therapy & $0.93(0.69-1.26)$ & 0.643 & & \\
\hline DAS28 at time of discontinuation & $0.81(0.49-1.36)$ & 0.430 & & \\
\hline
\end{tabular}

${ }^{1}$ Backward selection, variables with $p<0.20$ in univariable analyses were entered. ${ }^{2} \mathrm{HR}>1$ indicates prolonged biological survival; $\mathrm{HR}<1$ indicates reduced biological survival due to inefficacy or AEs. ${ }^{3} \mathrm{HR}>1$ indicates prolonged biological survival due to inability to taper; $\mathrm{HR}<1$ indicates reduced biological survival due to tapering of bDMARD due to remission. Bold numbers within the univariable column indicate HRs which had a $p<0.2$, bold numbers within the multivariable column indicate HRs with a $p<0.05$

$A C P A$ anti-citrullinated protein antibody, $A E S$ adverse events, $B M I$ body mass index, $C I$ confidence interval, DAS Disease Activity Score, $H R$ hazard ratio and uses a certain drug, the lower the adherence [18]. Furthermore, patients' beliefs on the efficacy of the drug could play a role $[19,20]$. For example, we already showed that biological survival improves if combined with a csDMARDs. And if patients believe that the csDMARDs are necessary, their compliance will increase, which will probably result in an even better biological survival.

Previous literature already showed that the presence of autoantibodies in RA is associated with a worse treatment response and outcome. Moreover, autoantibody-negative RA patients have a better treatment response compared to autoantibody-positive RA patients when given similar therapies [21]. In accordance with previous literature, we found a shortened biological survival due to inefficacy or adverse events in RF-positive RA patients but also the inability to taper TNF inhibitors after reaching remission in ACPApositive RA patients [22]. This reconfirms the fact that autoantibody positivity is associated with worse outcomes and indicates that RA can be subdivided into autoantibodypositive and autoantibody-negative RA. This also suggests that treatment maybe stratified on autoantibody status, but validation is needed.

In conclusion, bDMARD survival diminishes with the number of bDMARDs used. Combining a bDMARD with a csDMARD increases bDMARD survival, which supports current EULAR recommendations to combine a bDMARD with a csDMARD. RF and ACPA were negatively associated with respectively bDMARD survival and discontinuation due to remission. Therefore, the possible first step to personalized medicine in RA might be tailoring of treatment based upon autoantibody status.

Supplementary Information The online version contains supplementary material available at https://doi.org/10.1007/s10067-020-05567-6.

Acknowledgments The authors thank Annelieke Pasma for her help in the acquisition of the data.

Authors' Contributions EvM and SA were responsible for acquisition of data. EvM and PHPdJ statistically analyzed the data. All authors were responsible for interpretation of the data and for drafting, revising, and approving the final submitted manuscript. 
Data availability Data are available upon reasonable request by contacting the corresponding author.

\section{Compliance with ethical standards}

\section{Disclosures None.}

Ethical approval Ethical approval was obtained by the medical ethics committee of the Erasmus MC (MEC-2019-0573). It was not required to obtain written informed consent of participants.

Open Access This article is licensed under a Creative Commons Attribution 4.0 International License, which permits use, sharing, adaptation, distribution and reproduction in any medium or format, as long as you give appropriate credit to the original author(s) and the source, provide a link to the Creative Commons licence, and indicate if changes were made. The images or other third party material in this article are included in the article's Creative Commons licence, unless indicated otherwise in a credit line to the material. If material is not included in the article's Creative Commons licence and your intended use is not permitted by statutory regulation or exceeds the permitted use, you will need to obtain permission directly from the copyright holder. To view a copy of this licence, visit http://creativecommons.org/licenses/by/4.0/.

\section{References}

1. Smolen JS, Landewe RBM, Bijlsma JWJ, Burmester GR, Dougados M, Kerschbaumer A et al (2020) EULAR recommendations for the management of rheumatoid arthritis with synthetic and biological disease-modifying antirheumatic drugs: 2019 update. Ann Rheum Dis 79:685-699

2. Favalli EG, Pontikaki I, Becciolini A, Biggioggero M, Ughi N, Romano M, Crotti C, Gattinara M, Gerloni V, Marchesoni A, Meroni PL (2017) Real-life 10-year retention rate of first-line anti-TNF drugs for inflammatory arthritides in adult- and juvenileonset populations: similarities and differences. Clin Rheumatol 36(8):1747-1755

3. Favalli EG, Raimondo MG, Becciolini A, Crotti C, Biggioggero M, Caporali R (2017) The management of first-line biologic therapy failures in rheumatoid arthritis: current practice and future perspectives. Autoimmun Rev 16(12):1185-1195

4. Kalden JR, Schulze-Koops H (2017) Immunogenicity and loss of response to TNF inhibitors: implications for rheumatoid arthritis treatment. Nat Rev Rheumatol 13(12):707-718

5. Hyrich KL, Watson KD, Silman AJ, Symmons DP, British Society for Rheumatology Biologics R (2006) Predictors of response to anti-TNF-alpha therapy among patients with rheumatoid arthritis: results from the British Society for Rheumatology Biologics Register. Rheumatology (Oxford) 45(12):1558-1565

6. Hernandez MV, Sanchez-Piedra C, Garcia-Magallon B, Cuende E, Manero J, Campos-Fernandez C et al (2019) Factors associated with long-term retention of treatment with golimumab in a realworld setting: an analysis of the Spanish BIOBADASER registry. Rheumatol Int 39(3):509-515

7. Klareskog L, van der Heijde D, de Jager JP, Gough A, Kalden J, Malaise M, Mola EM, Pavelka K, Sany J, Settas L, Wajdula J, Pedersen R, Fatenejad S, Sanda M (2004) Therapeutic effect of the combination of etanercept and methotrexate compared with each treatment alone in patients with rheumatoid arthritis: doubleblind randomised controlled trial. Lancet. 363(9410):675-681
8. Specialisten FM. Reumatoïde Artritis (RA). Richtlijnendatabase; 2020 [updated 2020 30-10-2019; cited 2020 10-06-2020]; Available from: https://richtlijnendatabase.nl/richtlijn/reumato de_artritis_ra/startpagina__reumatoide_artritis.html

9. Dennis G Jr, Holweg CT, Kummerfeld SK, Choy DF, Setiadi AF, Hackney JA et al (2014) Synovial phenotypes in rheumatoid arthritis correlate with response to biologic therapeutics. Arthritis Res Ther 16(2):R90

10. Favalli EG, Biggioggero M, Marchesoni A, Meroni PL (2014) Survival on treatment with second-line biologic therapy: a cohort study comparing cycling and swap strategies. Rheumatology (Oxford) 53(9):1664-1668

11. Rubbert-Roth A, Szabo MZ, Kedves M, Nagy G, Atzeni F, SarziPuttini P (2019) Failure of anti-TNF treatment in patients with rheumatoid arthritis: the pros and cons of the early use of alternative biological agents. Autoimmun Rev 18(12): 102398

12. de Jong PH, Hazes JM, Han HK, Huisman M, van Zeben D, van der Lubbe PA, Gerards AH, van Schaeybroeck B, de Sonnaville PB, van Krugten MV, Luime JJ, Weel AE (2014) Randomised comparison of initial triple DMARD therapy with methotrexate monotherapy in combination with low-dose glucocorticoid bridging therapy; 1-year data of the tREACH trial. Ann Rheum Dis 73(7):1331-1339

13. van Mulligen E, de Jong PHP, Kuijper TM, van der Ven M, Appels C, Bijkerk C, Harbers JB, de Man Y, Molenaar THE, Tchetverikov I, Goekoop-Ruiterman YPM, van Zeben J, Hazes JMW, Weel AEAM, Luime JJ (2019) Gradual tapering TNF inhibitors versus conventional synthetic DMARDs after achieving controlled disease in patients with rheumatoid arthritis: first-year results of the randomised controlled TARA study. Ann Rheum Dis 78(6):746-753

14. Ghiti Moghadam M, Vonkeman HE, Ten Klooster PM, Tekstra J, van Schaardenburg D, Starmans-Kool M et al (2016) Stopping tumor necrosis factor inhibitor treatment in patients with established rheumatoid arthritis in remission or with stable low disease activity: a pragmatic multicenter, open-label randomized controlled trial. Arthritis Rheumatol 68(8):1810-1817

15. de Man YA, Dolhain RJ, van de Geijn FE, Willemsen SP, Hazes JM (2008) Disease activity of rheumatoid arthritis during pregnancy: results from a nationwide prospective study. Arthritis Rheum 59(9):1241-1248

16. Soliman MM, Ashcroft DM, Watson KD, Lunt M, Symmons DP, Hyrich KL, British Society for Rheumatology Biologics Register (2011) Impact of concomitant use of DMARDs on the persistence with anti-TNF therapies in patients with rheumatoid arthritis: results from the British Society for Rheumatology Biologics Register. Ann Rheum Dis 70(4):583-589

17. Iannone F, Gremese E, Atzeni F, Biasi D, Botsios C, Cipriani P et al (2012) Longterm retention of tumor necrosis factor-alpha inhibitor therapy in a large Italian cohort of patients with rheumatoid arthritis from the GISEA registry: an appraisal of predictors. J Rheumatol 39(6):1179-1184

18. de Thurah A, Nørgaard M, Johansen MB, Stengaard-Pedersen K (2010) Methotrexate compliance among patients with rheumatoid arthritis: the influence of disease activity, disease duration, and comorbidity in a 10-year longitudinal study. Scand J Rheumatol 39(3):197-205

19. Morgan C, McBeth J, Cordingley L, Watson K, Hyrich KL, Symmons DP et al (2015) The influence of behavioural and psychological factors on medication adherence over time in rheumatoid arthritis patients: a study in the biologics era. Rheumatology (Oxford) 54(10):1780-1791

20. Raghunath S, Hijjawi R, Hoon E, Shanahan EM, Goldblatt F (2019) Qualitative assessment of medication adherence in patients with rheumatic diseases on biologic therapy. Clin Rheumatol 38(10):2699-2707

21. Matthijssen XME, Niemantsverdriet E, Huizinga TWJ, van der Helm-van Mil AHM (2020) Enhanced treatment strategies and 
distinct disease outcomes among autoantibody-positive and negative rheumatoid arthritis patients over 25 years: a longitudinal cohort study in the Netherlands. PLoS Med 17(9):e1003296

22. Ogawa Y, Takahashi N, Kaneko A, Hirano Y, Kanayama Y, Yabe Y, Oguchi T, Fujibayashi T, Takagi H, Hanabayashi M, Funahashi K, Hayashi M, Tsuboi S, Asai S, Asai N, Matsumoto T, Sobue Y, Ishiguro N, Kojima T (2019) Association between seropositivity and discontinuation of tumor necrosis factor inhibitors due to ineffectiveness in rheumatoid arthritis. Clin Rheumatol 38(10):2757-2763

Publisher's note Springer Nature remains neutral with regard to jurisdictional claims in published maps and institutional affiliations. 